\title{
Study on Reform Idea of Drilling Engineering Course Based on Multidimensional Practice Teaching Platform
}

\author{
Guohua Wang \\ Petroleum Engineering School, Southwest Petroleum University, Chengdu, Sichuan, 610500, China
}

Keywords: multidimensional practice teaching platform; drilling engineering; course reform idea

\begin{abstract}
Drilling engineering is an important required course for majors of petroleum engineering. The course of drilling engineering mainly provides practice teaching of basic theoretical knowledge, computable knowledge, design knowledge, drilling technology knowledge and so on related to drilling engineering, to help students unify theory and practice. In teaching process, to create a new education mode and train students' practical ability and comprehensive quality, it is required to employ multidimensional practice teaching platform properly, give consideration to characteristics of the course in teaching work, innovate the educational mode and method, considerably raise the teaching level of drilling engineering course, and try our best to satisfy the requirements for talent training.
\end{abstract}

\section{Introduction}

Under the background of the application of multidimensional practice teaching platform, teachers should attach importance to the reform of drilling engineering course, develop an elaborate educational program, train students' theoretical knowledge understanding ability on practice teaching platform, practical ability, coordination skills, and comprehensive ability, and take full advantage of the achievements of course reform.

\section{Characteristics of Drilling Engineering Course}

Firstly, this course relates to much theoretical knowledge. Drilling engineering is a comprehensive course, mainly relating to geological environment knowledge, drilling tool knowledge, drilling fluid knowledge, drilling technology knowledge, well cementation and completion knowledge, engineering design knowledge, and special drilling technology knowledge. Under the support of geology and rock mechanics, the course relates to much theoretical knowledge, and the subject contents appear to be interdisciplinary. Besides, many computational formulas will be related to. All these factors appear to be difficult to most students, which is liable to affect teaching effect. Only in a proper teaching mode, desired teaching effect of theoretical knowledge can be achieved.

This part is about the practical characteristics of the course. The course mode of drilling engineering is highly comprehensive. It covers much abstract knowledge, and proceeds under the support of practice. Lectures of theoretical knowledge without actual practice are bad for students in learning and achieving desired teaching effect.

Thirdly, the knowledge of this course keeps updating rapidly. From the view of technological development, drilling is an important link of petroleum exploration and development. Thus, drilling tools, machineries and equipment can be updated rationally. A mode of innovative development of technology has been formed. However, if the contents of the course fail to be updated properly, the whole teaching effect will be affected; if teaching activities fail to be carried out properly, the whole teaching quality also will be affected. 


\section{Teaching Reform Goals of Drilling Engineering Course}

Based on the knowledge of the characteristics of drilling engineering course, to comprehensively improve the teaching effect, concrete reform goals should be set, so as to develop a scientific and rational teaching mode. The reform goals are:

Firstly, the reform is carried out to train students' theoretical knowledge acquisition ability. In traditional classroom teaching process, teachers mainly deliver lectures throughout the whole class, seldom reform and innovate classroom teaching mode properly, and fail to treat students as dominant role to arouse students' enthusiasm, only to make teaching work dull. This is adverse for teachers to fulfilling teaching tasks, makes impossible for teachers to help students link all knowledge and properly control the teaching process, and is bad for students to master theoretical knowledge. Therefore, in the process of teaching reform, teachers should make efforts to train students' theoretical knowledge on the whole, improve teaching effect, try best to help students concentrate and arouse students' interest in learning by explaining theoretical knowledge in a scientific way. To this end, teachers can reform lectures on abstract knowledge properly in combination with lectures on theoretical knowledge, perform development and research in a rational way based on innovation, and create a scientific and rational work system, to coordinate teaching of theories of various aspects and raise the comprehensive work quality by means of scientific teaching of theoretical knowledge. As to theory teaching reform, teachers can help students to develop learning interest and improve classroom teaching effect with the aid of picture, video and animation. Besides, teachers should focus on training students' independent learning ability in classroom teaching, help students make certain their development direction based on their learning needs, develop a thorough teaching plan, and make efforts to improve the teaching quality of theoretical knowledge.

Secondly, the reform is carried to train students' practical ability. In classroom teaching process of drilling engineering course, teachers should focus on training students' practical ability as the main goal. Under the support of basic formula and actual practice teaching, a rational education system can be formed, which can ensure the improvement of the quality of actual practice education in the new period. Actual practice teaching mainly relates to computation of drilling fluid density, viscosity and pipe diameter. Many parameters will be involved, which is difficult to remember. In traditional teaching, most students have difficulties about computational formula, and fail to form adequate practical ability. Therefore, teachers can, with the aid of multidimensional practice teaching platform, illustrate calculation idea, get across the meaning of formulas, and make rational analysis of extreme points of objective function mathematically under uniform working standard and with established objective function, to help students master practical ability, and improve the teaching quality of drilling engineering course. In this process, teachers should attach importance to training students' learning method, optimize teaching parameters in teaching as far as possible, assign practical tasks to students, and organize practical activities to strengthen teaching results.

Thirdly, the reform is carried out to train students' intuitive learning ability. Teachers of drilling engineering should try to train students' intuitive learning ability in teaching process, make full use of multidimensional practice teaching platform in teaching, develop a sound work program, and train students' learning ability with modern practice teaching tools, so as to improve education quality and level, and promote rational reform of drilling engineering course.

\section{Reform Idea of Drilling Engineering Course under the Background of Multidimensional Practice Teaching Platform}

Under the background of multidimensional practice teaching platform, teachers should attach importance to the reform of drilling engineering course, create a scientific and rational working mode, and train students to form strong practical ability, to satisfy the needs of drilling engineering course reform. The proposed measures are: 


\subsection{Reform of teaching mode}

In traditional teaching mode, teachers deliver lectures on the platform, and students passively receive knowledge. In other words, it is a "duck-stuffing" type of teaching. It is the case that most teachers divide knowledge points into key content, difficulties, and content for comprehension in classroom teaching of drilling engineering course. Teachers take it for granted that students can form learning motivation as long as they keep in mind knowledge points and pass examination. In this way, it is impossible to establish an appropriate course learning mechanism. However, the classroom teaching of drilling engineering course requires engineering practice. If students just learn to memorize mechanically, they can never become a good learner. Therefore, it is necessary to reform and innovate teaching mode.

Firstly, measures should be taken to help students concentrate. Teachers should combine classroom teaching content with learning content, illustrate the meaning of classroom teaching content to students, guide students to develop practical ability on the multidimensional practice teaching platform, apply theoretical knowledge into practice properly, and help students concentrate, to ensure teaching effect.

Secondly, the multidimensional practice teaching platform should be made full use of to arouse students' interest in learning and promote interaction between teachers and students. In classroom teaching, theoretical knowledge and practice should be combined, and the teaching mode should be innovated in addition to the improvement of classroom teaching content to ensure active classroom atmosphere. It is recommended to design some interaction activities, to attract students to participate in classroom teaching. Besides, teachers should focus on theoretical knowledge in teaching process, accompanied by actual practice. For example, during lectures on drilling engineering knowledge, teachers can divide students into several groups, allow students to raise questions and voice their opinions, with a view to encourage students to participate in teaching, arouse students' enthusiasm, and develop students' thinking ability. Teachers also should recognize students' problems in learning, and take proper measures to adjust teaching content accordingly.

Thirdly, teachers should innovate and reform teaching content on the multidimensional practice teaching platform to set examples properly, add information with the aid of computer and network technique to facilitate teaching. Teachers should collect resources on drilling engineering on network platform as far as possible to support their teaching at different stages. For example, teachers can impart drill pipe stress knowledge and deformation phenomenon knowledge on the multidimensional practice teaching platform, and train students to develop intuitive learning ability with the aid of picture and video. In a word, the goal of reform is to simplify teaching process and achieve better effect.

Fourthly, on the multidimensional practice teaching platform, teachers should apply theoretical knowledge into practical teaching properly, create a teaching mode particular to practice link, combine theoretical knowledge and practical teaching, and simulate an engineering field, to combine classroom teaching with field operation and form a contrast. In the process of field practice teaching, teachers should reform and innovate the teaching mode. For example, teachers can invite experienced experts to deliver lecture to help students improve their knowledge comprehension ability via practice, and coordinate various aspects of teaching ${ }^{[1]}$.

Fifthly, the teaching reform should be refined by creating a scientific and rational education program adjustment scheme on the multidimensional practice teaching platform, enrich the content of drilling engineering teaching, developing a perfect strategy scheme, and thoroughly optimizing the education mode. With the aid of the multidimensional practice teaching platform, teaching innovation can be made in a scientific and rational way, so as to train students' professional ability ${ }^{[2]}$.

\subsection{Increase of practice amount}

In the process of classroom teaching of drilling engineering course, teachers should, with the aid of the multidimensional practice teaching platform, fully understand students' learning progression, 
adjust the talent training program and plan properly, organize class exercise to identify teaching vulnerabilities or problems in time, and take proper measures to realize reform and innovation. In routine teaching, teachers should pay attention to auxiliary information as the main content to help students develop learning ability, guide students to apply theoretical knowledge into practice, and enhance students' comprehension ability by consolidating classroom teaching content. In the process of classroom teaching, teachers should sum up experience, develop a teaching mode of drilling engineering course, and create a professional drilling engineering practice teaching system based on the experience and with the aid of various teaching methods. Meanwhile, in the process of drilling engineering specialty teaching, teachers need to select proper examples and exercises, and design a proper problem set, so as to impart proper knowledge points to students while helping students develop learning ability and create a scientific teaching mode while preventing teaching problems ${ }^{[3]}$.

\subsection{Reform of examination system}

In the teaching process of drilling engineering course, teachers should make a perfect course reform scheme, reform the examination system properly, and establish a perfect work plan, to improve work efficiency in various aspects; guide students to support each other to help them develop learning ability and practical ability and master advanced learning skills. In order to train students' learning ability via the multidimensional practice teaching platform, teachers should abandon the utilitarian teaching assessment mode, and turn to a scientific and innovative method for reflecting students' state. With definite teaching objectives, teachers should select an optimum examination mode. For example, teachers can conduct experiment test, to force students to improve their learning ability via practice; or focus on the training of students' comprehension ability and problem solving ability with an incentive of increasing mark. Teachers should create a scientific teaching mode on the multidimensional practice teaching platform, so as to train students' practical ability in a rational way and keep pace with the times.

\subsection{Reform of practice teaching}

In the teaching process of drilling engineering course, teachers should innovate and reform practice teachings properly, set definite teaching objectives, make certain teaching characteristics, and create a standardized practice teaching mode based on rational analysis and research, so as to improve teaching quality and practice teaching quality. Meanwhile, in the process of practice teaching reform, teachers should guide students to develop practical ability, and optimize allocation of teaching resources for purpose of training students' practical ability, so that students are able to take part in practice in industrial environment. On the premise of combining theory with practice, teachers can, in line with the principle of training high quality talents, organize particular practice activities, and create a scientific talent training mechanism, which will make for improving the practice teaching mode and training students' learning ability. Besides, in the process of practice teaching innovation, teachers should establish a rational teaching mode, find teaching problems timely, take proper countermeasures, and take the opportunity of modern course reform to improve the quality of work ${ }^{[5]}$.

\section{Summary}

With the presence of multidimensional practice teaching platform, teachers should perform reform and innovations relating to drilling engineering course, make a perfect practice teaching scheme, obey modern working principle in the process of scientific research and innovation, and train students' comprehensive quality.

\section{Acknowledgement}

This research was financially supported by School-level Educational Reform Project of Southwest 
Petroleum University-Reform and Practice of Teaching Method of Offshore Drilling Engineering Course (Grant NO.2016JXYJ-02).

\section{References}

[1] Song Chuanling. Reform and Practice of Multidimensional Practice Teaching System of the Specialty of Computer Application Based on Innovation and Entrepreneurship Ability Training, Journal of Shandong Institute of Commerce and Technology, 2017, 17(3):29-31.

[2] Cai Qian, Liu Yuqiang. Creation of Multidimensional Practice Teaching Platform for Pharmaceutical Specialty Based on Innovation Ability Training, Education Teaching Forum, 2017 (10): 193-194.

[3] Wen Xue, Xie Jing. Study on Practice Teaching of Electronic Commerce Based on Multidimensional Entrepreneurial E-commerce Platform, Journal of Beijing Institute of Graphic Communication, 2017, 25(6):146-148.

[4] Guo Qun. Reform and Practice of Multidimensional Teaching Mode Based on Case Study of the Course of Data Structure, Folder, 2017(18).

[5] Lyu Haiting, Cheng Rui. Study on Innovation Ability of Engineering Majors Based on Multidimensional Practice Platform, Science and Technology, 2017, 27(7). 